\title{
General Deterrence and Corporate Environmental Behavior*
}

\author{
DOROTHY THORNTON, NEIL A. GUNNINGHAM, and \\ ROBERT A. KAGAN
}

\begin{abstract}
This research addresses the assumption that "general deterrence" is an important key to enhanced compliance with regulatory laws. Through a survey of 233 firms in several industries in the United States, we sought to answer the following questions: (1) When severe legal penalties are imposed against a violator of environmental laws, do other companies in the same industry actually learn about such "signal cases"? (2) Does knowing about "signal cases" change firms' compliancerelated behavior? It was found that only 42 percent of respondents could identify the "signal case," but 89 percent could identify some enforcement actions against other firms, and 63 percent of firms reported having taken some compliancerelated actions in response to learning about such cases. Overall, it is concluded that because most firms are in compliance already (for a variety of other reasons), this form of "explicit general deterrence" knowledge usually serves not to enhance the perceived threat of legal punishment, but as reassurance that compliance is not foolish and as a reminder to check on the reliability of existing compliance routines.
\end{abstract}

In most regulatory programs, officials formally prosecute and obtain legal sanctions against violators in only a small percentage of infractions. They deal with most detected violations at the bottom of the "pyramid of sanctions" (Ayres \& Braithwaite 1992) - that is, by means of warnings, demands for remedial action, repeated re-inspection, and other informal pressures. At the same time, most regulatory officials and regulatory scholars believe that governmental capacity to impose severe legal penalties, together with relatively frequent use of that capacity, is crucial to the implementation of regulatory norms. Pro-regulation advocacy groups often complain that regulatory effectiveness suffers because violations are prosecuted too infrequently and penalized too lightly.

\footnotetext{
* This work was supported by the U.S. Environmental Protection Agency's STAR Grant Program and the Center for the Study of Law and Society at University of California, Berkeley. The authors are also grateful to Manuel Vallee and Peter Younkin, who conducted the bulk of the survey interviews and provided other equally excellent research support.

Address correspondence to Neil Gunningham, REGNET, University House, Australian National University, Canberra ACT 0200, Australia; e-mail: neil.gunningham@anu.edu.au 
There is surprisingly little research, however, that tells us precisely how important the threat of large legal sanctions really is in motivating regulated business firms to comply with the law. This article, together with a companion article (Gunningham, Thornton \& Kagan 2005), reports the results of a research project designed to explore that question.

\section{EXPLAINING REGULATORY COMPLIANCE: GENERAL DETERRENCE AND ALTERNATIVE HYPOTHESES}

The basic theory of general deterrence rests on the notion that regulated business entities are profit-driven "amoral calculators" (Kagan \& Scholz 1984). Thus, only fear of imminent legal penalties that exceed the cost of compliance can induce profit-seeking firms to invest in compliance with regulatory demands. Each tough legal penalty, it is assumed, sends a "threat message" that reverberates through the community of regulated businesses. As the perceived risk and cost of violations thereby increases, business executives increase their investments in compliance.

On the other hand, a considerable body of socio-legal scholarship suggests rather different hypotheses about compliance-related behavior. Although the research reported in this article was designed primarily to probe the standard general deterrence theory, it will be useful first to review some of the alternative theories that question it.

\section{A. OTHER FEAR-BASED THEORIES}

Some alternative theories retain the assumption that fear of legal sanctions is the primary driver of compliance-related behavior, but question the potency of the standard general deterrence model. For example, amidst the cacophony of news, information, and demands of contemporary society, one might wonder whether business firms actually learn about and attend to legal penalties imposed on other firms in other places. Even if they do, business executives may not think that their firm-which may differ in many ways from the sanctioned firm-faces an enhanced risk of being found in violation and punished (see Braithwaite \& Makkai 1991). Thus, against the general deterrence thesis, which assumes widespread dissemination and attention to clear deterrence messages, one might counterpose a "weak signal, weak threat" hypothesisthat is, the message often does not get through or send a meaningful threat.

Second, some research indicates that the chief driver of enhanced compliance efforts by regulated firms is not general deterrence (hearing about legal sanctions against others) but "specific deterrence"- the fear engendered by the prior experience of being inspected, warned, or penalized themselves that is the chief driver of enhanced compliance efforts (Gray \& Scholz 1991; Gray \& Shadbegian 2004; Mendeloff \& Gray 2004). ${ }^{\prime}$

Third, some research indicates that many corporate officials regard the risk of informal social and economic sanctions as far more salient and 
threatening than the risk of legal penalties. Negative publicity concerning environmental harm caused by business facilities can alienate the firm's host community, result in loss of market share, and stimulate closer, more suspicious scrutiny by regulators. Hence many corporate officials speak of complying not only with regulations but with their "social license"-public expectations concerning decent environmental performance, "enforced" in a variety of ways by environmental activists, journalists, local politicians, and sometimes by customers (Gunningham, Kagan \& Thornton 2003). Corporate concern for maintaining a reputation as a good environmental citizen helps explain why many firms nowadays regard "overcompliance" with regulatory obligations as a good business strategy (ibid. 2003; Mehta \& Hawkins 1998; Prakash 2000). ${ }^{2}$ As a result of these concerns, general deterrence messages often may be redundant, exerting little impact on corporate compliance behavior.

\section{B. DUTY}

Evidence abounds that regulatory violations by business firms are far from infrequent. ${ }^{3}$ At the same time, studies indicate compliance with regulations is much more common than deterrence theory would lead one to expect; relatively high levels of regulatory compliance exist even when the threat of legal enforcement appears to be remote. ${ }^{4}$ One possible explanation, referred to above, is that many firms fear the negative publicity and the social, political, and economic sanctions that can flow from serious violations. Another explanation, suggested by a variety of scholars, is that for most firms, compliance stems not from fear of legal sanctions, but from a sense of social or legal obligation. Socio-legal research indicates that in democratic societies with a strong rule of law tradition, most business managers have "internalized" (or agree with) the social norms that under-gird many regulatory rules. Such social norms, as articulated by Vandenbergh $(2003$ : 88, 95) include "An individual should not cause harm to human health," and "An individual should not harm the environment." Moreover, most business executives in the United States, it is not unreasonable to believe, are generally committed, as a matter of socialization and citizenship, to complying with duly enacted laws and regulations (Malloy 2003: 464-75). Furthermore, officials in charge of corporate compliance efforts often are professionals-environmental engineers, safety experts, and so on-who, like the chief nurses in the Australian nursing homes studied by Braithwaite and Makkai (1991), have a strong sense of duty about compliance with regulatory norms. ${ }^{6}$ May (2004) found that residential construction company officials, in describing their motive to comply with building code provisions, ranked "duty to comply with building requirements" (as well as maintaining a reputation for quality) as much more important than fear of regulatory fines. For firms sensitive to their normative obligations, too, one might hypothesize that general deterrence signals are redundant, adding little, if anything, to compliance efforts. 


\begin{tabular}{|c|c|c|c|}
\hline \multirow{3}{*}{ DUTY } & high & $\begin{array}{l}\text { deterrence weak } \\
\text { but redundant } \\
\text { (a) }\end{array}$ & $\begin{array}{l}\text { deterrence effective } \\
\text { but redundant } \\
\text { (c) }\end{array}$ \\
\hline & low & $\begin{array}{l}\text { deterrence } \\
\text { ineffective } \\
\text { (d) }\end{array}$ & $\begin{array}{l}\text { deterrence effective } \\
\text { (b) }\end{array}$ \\
\hline & & low & high \\
\hline
\end{tabular}

FEAR

Figure 1. Fear, Duty, and the Role of General Deterrence.

\section{MIXED MOTIVES}

While some alternative theories of corporate compliance focus on fear of legal sanctions (general and specific deterrence) and social sanctions, and other theories focus on the potency of felt normative obligations, another approach would emphasize the interaction of "fear" and "duty" and of variation in motives across firms. Consider the schematic diagram in Figure 1, which posits that, in principle, firms might display one of four combinations of duty and fear of sanctions. This suggests that deterrence models would be meaningful for those firms that score high on fear, but ineffective for those that are low on fear, and they would be redundant for those that are high on duty. ${ }^{7}$

\section{Implicit General Deterrence}

If many firms are motivated by both fear and duty, general deterrence messages may matter but in a much more diffuse, non-specific manner than that suggested by classic deterrence theory. Imagine that many businesses are motivated by a combination of fear of sanctions (legal and social) and of felt obligations to comply with most regulations. ${ }^{8}$ In polities like the U.S. with a rich tradition of the rule of law and a history of significant regulatory enforcement, such business firms might simply assume that (1) governmental regulations (or the statutes that give rise to them) prescribe legal sanctions for violations, (2) significant violations of those regulations entail a fairly substantial risk of detection and punishment (and of related reputational costs), and (3) it is both prudent and right to commit to a policy of full compliance. For officials at Firm A, then, simply learning about an applicable regulatory requirement evokes some level of perceived threat (plus a felt legal obligation), inducing it to increase its compliance-related efforts-much as a motorist in a strange city or country responds to posted speed limits and other traffic signs. Firm $\mathrm{A}$, therefore, would respond to the regulation regardless of whether it hears about specific punishments of Firms B and C for violating that rule. Such an "implicit general deterrence" mechanism 
can be contrasted with the "explicit general deterrence theory" mentioned at the outset, which assumes that learning about punishments against Firms $\mathrm{B}$ and $\mathrm{C}$ will increase A's fear that violations will be detected and punished, motivating A to comply. In the "implicit general deterrence" theory, however, variation in the frequency and severity of sanctions may have little effect, as firms pay more attention in formulating their compliance strategies to social, economic, and normative pressures-rather than carefully matching compliance expenditures to their calculations of the precise level of legal risk.

\section{The "Reminder" Function of General Deterrence Messages}

Assume that because of the combination of legal threat, normative obligation, and concern for preserving their reputation as good corporate citizens, most enterprises in the contemporary United States are committed to comply with most governmental laws and regulations. That is not inconsistent with the repeated finding, noted earlier, that violations of environmental regulations are common. A great many violations occur, a number of studies indicate, because corporate managers' commitments to comply with the law, even if embodied in corporate policies or prescribed routines, are neglected by individual employees or sub-units that are subject to conflicting pressures, or who misunderstand what precisely is required by a complex and changing array of federal, state, and local regulatory demands (Malloy 2003; Spence 2001: 972-73). ${ }^{9}$ When that is the case, explicit general deterrence messages may not motivate firms to comply, but they may serve as a reminder of preexisting commitments to comply. ${ }^{10}$ Thus learning about legal penalties against Companies $\mathrm{B}$ and $\mathrm{C}$ may lead managers in Company $\mathrm{A}$ to check whether their compliance routines are being followed.

\section{The "Reasssurance Function" of General Deterrence Messages}

Lastly, one might imagine that explicit general deterrence messages matter not because of the threat they signal but because of the symbolic reassurance they provide to companies that make costly compliance-related investments. Learning of penalties against Firm B reassures A that it will not be at a competitive disadvantage vis-à-vis firms who cut costs by violating the law. Chester Bowles (1971: 25), reflecting on his job as head of the U.S. Office of Price Administration during World War II, said that 20 percent of the population would comply with any regulation, 5 percent would attempt to evade it, and the remaining 75 percent would go along with it as long as the 5 percent were caught and punished. ${ }^{10}$ Officials on other regulatory agencies often echo that theory, arguing that penalizing the "bad apples" helps keep the "contingently good apples" good (Bardach \& Kagan 2002). Thus, the reminder and reassurance functions interact to support and reinforce the assumptions of implicit general deterrence: that rules have associated sanctions, sanctions are enforced, and that compliance is both prudent and right. 


\section{Examining Explicit General Deterrence}

The general theoretical issue, then, is how potent are "explicit general deterrence" mechanisms as compared to the alternatives mentioned. The research reported in this article is not structured as a rigorous test of the various hypotheses, or even of the explicit general deterrence hypothesis. It does represent, however, some first steps toward exploring the effects of explicit general deterrence messages. To that end, we chose eight significant enforcement actions and penalties ("signal cases") announced by the U.S. Environmental Protection Agency (EPA) between June and December of 2000. We then conducted a telephone survey of officials in 233 business firms in the same industries as those that had been penalized in the signal cases. In addition to this survey, we conducted in-depth interviews with officials at eighteen chemical manufacturing facilities and seventeen electroplating facilities in the states of Washington and Ohio, gathering more detailed information about their motivations and responses. ${ }^{12}$ The results of these more detailed interviews are discussed in Gunningham, Thornton, and Kagan (2005). We draw on that article however, in the discussion and conclusion of this article.

In the eight-industry survey discussed in this article, we focused on the following general issues:

1. When regulatory penalties are imposed against a particular violator, to what extent do other companies in the same industry actually learn about it?

2. Do respondents who know of regulatory enforcement actions against other firms have, on average, higher perceptions of the risk of detection and legal sanction than those who know of fewer enforcement actions?

3. Are respondents who know of regulatory enforcement actions against other firms more likely, on average, to have taken environmental compliance actions in response to hearing of such enforcement actions?

\section{METHODOLOGY}

\section{A. THE SIGNAL CASES}

To identify the "signal cases," we examined all U.S. EPA headquarters press releases from January 2000 through June 2001 that announced final enforcement actions $(n=112) .{ }^{13}$ From these, we selected eight, issued between June 2000 and December of $2000 .{ }^{14}$ The eight were chosen to include a variety of industries, localities, and penalties. We particularly wished to include some prosecutions for behavior that would not be seen as obviously criminal. Table 1 describes the infractions and the penalties assessed in these "signal cases."

For each signal case, we identified all facilities in the same state and industry, relying on a variety of sources. ${ }^{15} \mathrm{~A}$ random sample of these facilities was contacted by telephone, seeking the "person responsible for environmental compliance" at each facility. Officials in 233 facilities agreed to be interviewed, 


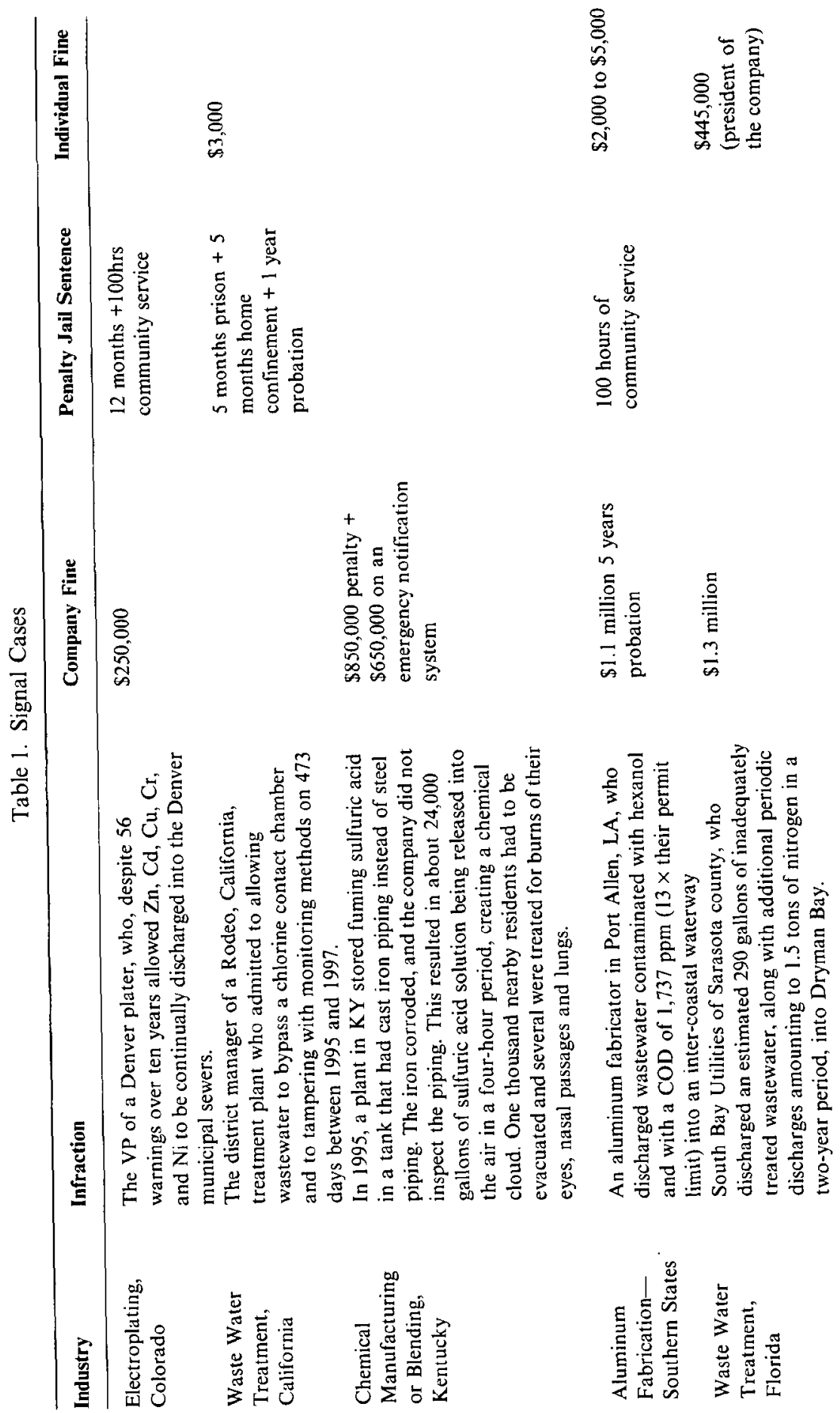

(C) 2005 Baldy Center for Law and Social Policy and Blackwell Publishing Ltd. 
Thornton, Gunningham \& Kagan DETERRENCE 269

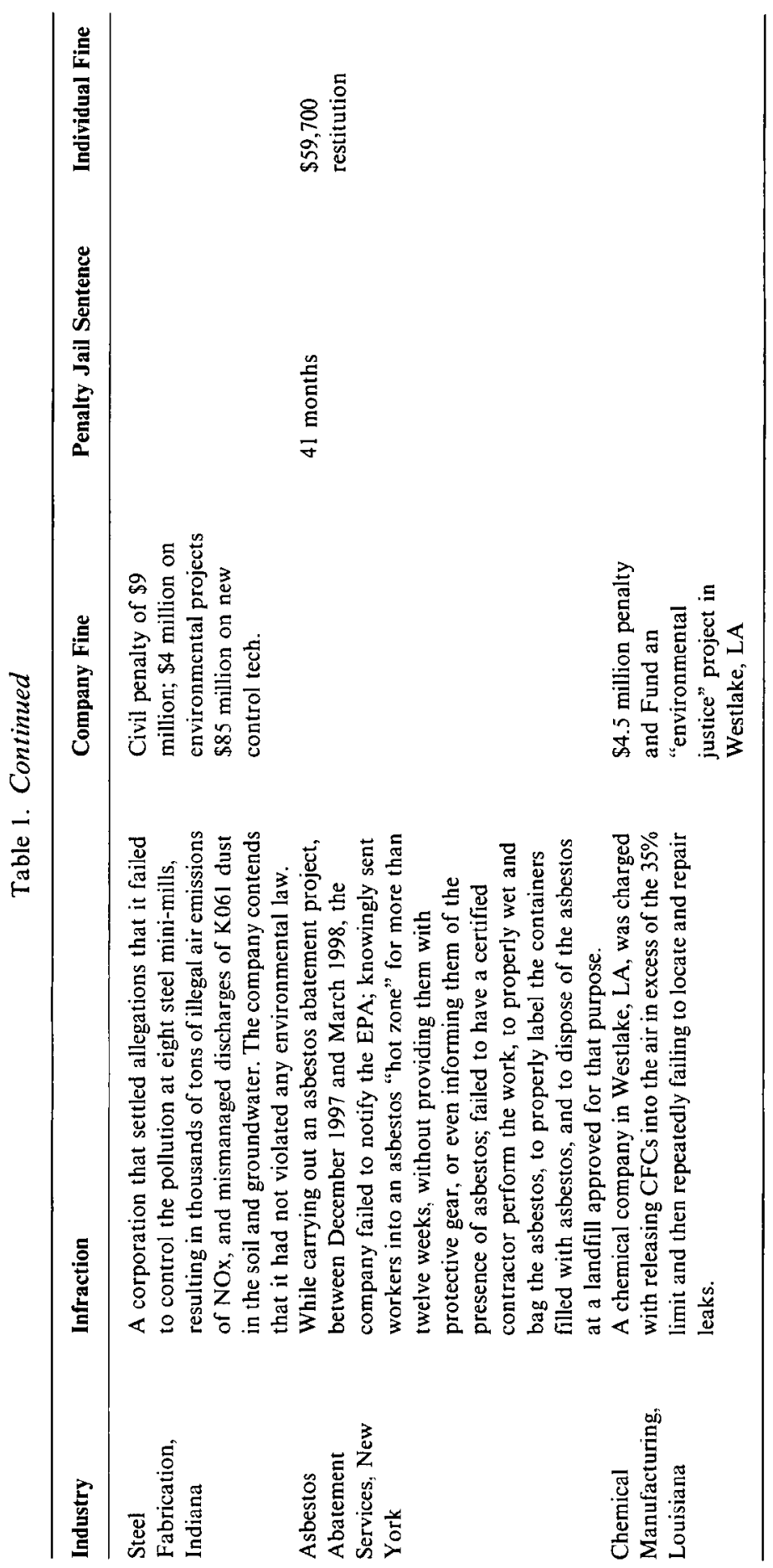


a response rate of 80 percent. ${ }^{16}$ Approximately 70 percent of the facilities whose officials we interviewed had fewer than 100 employees; and only those in the chemical industry had a significant ( 25 percent) proportion with more than 1,000 employees.

\section{B. MEASURING KNOWLEDGE OF ENFORCEMENT ACTIONS}

To assess respondents' knowledge of regulatory enforcement action against other firms, we employed three related but distinct measures:

\section{Quantum of Knowledge}

Respondents were asked: "In the last year or two, about how many instances can you think of where a company, anywhere in the U.S., was fined for an environmental problem." The question was repeated with respect to recollection of individuals who had been fined in their personal capacity or imprisoned.

\section{Knowledge of Particular Examples}

Respondents were asked if they could recall a particular example of a person or plant being penalized for an environmental crime. Beyond that, they were not prompted. If they could recall an example, they were then asked what the company had done that led to the penalty, what the penalty was, and when and where the event had occurred.

\section{Signal Case Knowledge}

Respondents were given a description of the infraction that had led to the EPA press release case for their industry. Respondents were then asked if they recognized the signal case.

\section{DEMOGRAPHIC VARIABLES}

With respect to their own companies, respondents were asked:

1. The number of people employed by the company as a whole (company size). Companies were then divided into two categories: small-less than 100 employees, or large -100 or more employees.

2. What percentage of their time they spent of environmental work (degree of environmental professionalism).

\section{RISK PERCEPTION VARIABLES}

A number of questions sought to assess respondents' perception of various legal risks associated with regulatory enforcement: 
1. Perceived Risk of Facility Closure. Respondents were asked: "In practice, on a scale of 0 to 100 , how often do you think that legal environmental penalties lead to a plant being shut down?"

2. Perceived Risk of Detection. Later, respondents were asked to consider a hypothetical situation modeled on the signal case. For example, chemical manufacturers and blenders in Louisiana were asked: "Assume for a moment that there was a chemical manufacturing plant that released CFCs into the air, $35 \%$ in excess of their permit limits, and then repeatedly failed to locate or repair the leaks that led to this excess. On a scale of 0 to 100 , what do you think the chances are that the plant would be found out by law enforcement?"

3. Perceived Risk of Company Fine (for the same scenario). "If they were found out, on a scale of 0 to 100 , what do you think the chances are that the plant would be fined? "Can you give me a ballpark estimate of how much they might be fined-hundreds, thousands, tens of thousands, millions?"

4. Perceived Risk of Incarceration. "If they were found out, on a scale of 0 to 100 , what do you think the chances are that the plant operator/owner, would be sent to jail or prison? Can you give me a ballpark estimate of how long he might serve-weeks, months, years?"

5. Perceived Risk of Individual Fine. "If they were found out, on a scale of 0 to 100 , what do you think the chances are that the plant operator/owner, would be fined? Can you give me a ballpark estimate of how much he might be fined-hundreds, thousands, tens of thousands, millions?"

\section{E. ENVIRONMENTAL ACTIONS IN RESPONSE TO DETERRENCE SIGNALS}

At the end of our interviews, after asking respondents if they recalled a signal case, respondents were asked if hearing about a fine or prison sentence at another company in their industry ever made them respond by: (1) reviewing their environmental programs; (2) changing their management plans; (3) changing how they kept track of or monitored things; (4) changing their employee training; (5) changing their equipment; or (6) changing their physical plant in some other way. We regarded a company as having "taken an environmental action" if they reported having taken any of the actions listed above.

Figure 2 summarizes how we operationalized the classic deterrence theory model, using the variables and measures discussed above.

\section{FINDINGS}

\section{A. KNOWLEDGE OF ENFORCEMENT ACTIONS}

Almost all ( 89 percent) of our 233 respondents remembered at least one instance of a fine against some other company, 64 percent recalled at least one fine imposed on an individual company official, and 31 percent remembered a prison sentence. On the other hand, firms' quantum knowledge of fines against other companies 


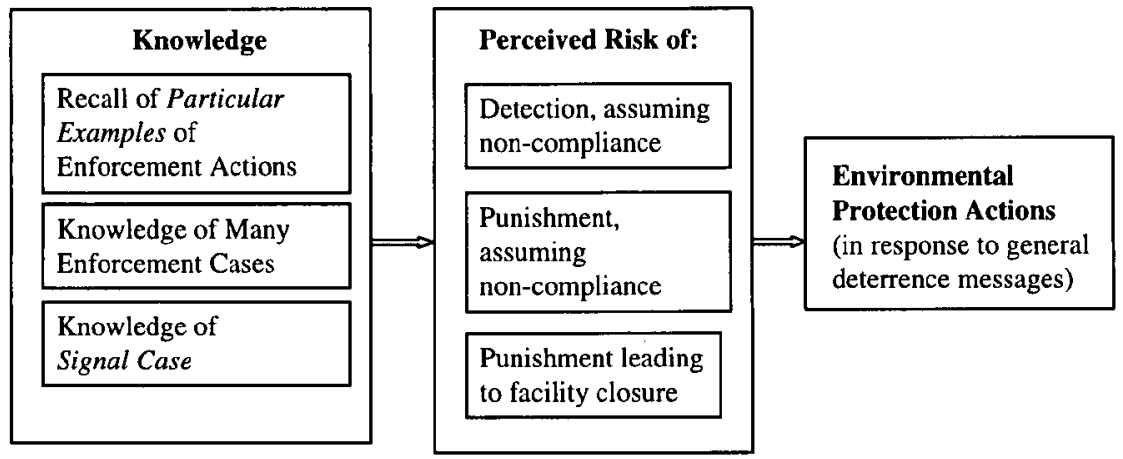

Figure 2. Classic Deterrence Model Operationalized

did not appear to be very accurate in terms of the frequency of fines or their magnitude. Respondents report having heard of far fewer fines than actually occur. For example, the median number of fines against other companies (anywhere in the United States, in the last year or two) that respondents could recall was only eight. Yet in Louisiana alone, in a one-year period (July 2001 through June 2002), thirty-one companies were fined for environmental infractions. ${ }^{17}$

The majority of respondents (71 per cent) could describe at least one particular example of a person or business being penalized for an environmental offense. However, if we examine the particular cases respondents described, it becomes clear that, on the whole, they tended to remember only those with unusually large financial penalties and/or cases where someone was sentenced to jail. Of the 107 respondents who gave a magnitude estimate, 43 percent cited fines of $\$ 1$ million or more, 67 percent cited fines of $\$ 100,000$ or more, while 26 percent of respondents who could describe a specific enforcement action noted that someone at the other company had been incarcerated. At the same time, respondents overwhelmingly underestimated the actual penaltics when the signal cases were presented as hypotheticals. Clearly, then, respondents have not been particularly attentive to penalty information. Nor have they made special efforts to obtain timely and accurate information. Thus consciousness of the possibility of a significant penalty was high, but remarkably inaccurate, in the industries sampled. ${ }^{18}$

When respondents cited the examples of penalty-inducing non-compliance by other firms, their accounts were often judgmental in tone, suggesting support for underlying social norms condemning harm to the environment and complying with law. For example:

Bottom line was they didn't care and they did something that they thought they would not get caught for.

Illegal removal of asbestos, dry removal (which is a violation), improper disposal, improper personnel. [Interviewer: is this all in the same case?] No, different cases, but you'd be surprised at what the EPA and DEP agents will find on a site. It's unbelievable. 
Dumping in the creek. It killed bunches of fish.

They had an accident due to mismanagement, let hundreds of gallons of sewage go into the ocean. It was on the news.

Not sure [what he did] but I think he screwed up and then tried to cover it up.

They polluted the local rivers with chemicals.

Burying toxic waste in ground and it leaked into the water.

These comments also seem to support the notion that explicit general deterrence messages serve a "reassurance function," informing contingent "good apples" (firms committed to compliance for a combination of normative, reputational, and "implicit general deterrence" reasons) that they are not foolish for doing so, since their competitors who "cheat" are getting caught and punished.

Strikingly, diffusion and memory of the signal case was far from ubiquitous. On average, only 42 percent of respondents recognized the specific EPA "signal case" (see Table 1, above) in their industry. ${ }^{19}$ One reason may be that the signal cases, despite their seriousness, generally did not get widespread publicity in the news media. ${ }^{20}$

Of the respondents who were able to describe at least one particular example of an enforcement action against another firm, 97 percent remembered the infraction that led to the enforcement action, while somewhat fewer-83 percent-recalled the penalty given as a result of the enforcement action. Of the eighty-seven respondents who said they had heard of the signal case, only 61 percent believed they could remember the penalty in the case.

In sum, although 58 percent of respondents did not recognize a vignette based on the signal case, previous penalties against other firms have a cumulative effect: most firms are quite aware that environmental penalties have been imposed on violators. At the same time, recollection of sanctions against other firms tend to be general: respondents remember the infractions more fully than the precise penalty, and they are more likely to think of instances of fines against companies than fines against individuals or incarcerations. Indeed, a significant minority of respondents could not recall any particular instance of a penalty against an individual. ${ }^{21}$ Thus the general deterrence message as received is somewhat weak and diffuse, but loud enough to create a noticeable background noise, so that most firms are aware of its existence. Our in-depth interviews in two industries revealed a similar effect (Gunningham, Kagan \& Thornton 2005).

\section{B. RISK PERCEPTION}

Most respondents did not think that environmental penalties would result in the closure of an offending facility. ${ }^{22}$ On the whole, however, respondents perceived the probability of detection for serious infractions, such as those described in the signal case, to be high; the median perception of detection risk was 70 percent. However, respondents' risk-of-detection perceptions were highly variable, ranging from close to 0 to 100 percent in most industries. 
Respondents generally felt that if a serious infraction resembling the signal case were to be detected, the offending company would be penalized: 92 percent of respondents felt the odds of a company fine were greater than 50:50. But respondents were far less certain that an individual company official or owner would be fined: 7 percent of respondents believed there was no possibility of an owner or operator being fined in their personal capacity, while 11 percent of respondents believed he would certainly be fined. The median risk-of-individual-fine perception was 40 percent. Respondents were even less certain that an individual would be incarcerated: 53 percent of respondents believed that the chance that an owner or operator would be incarcerated for a serious environmental infraction was 10 percent or less. ${ }^{23}$

Respondents' expectations of the magnitude of company fines covered an enormous range, from $\$ 0$ to $\$ 20$ million, and similarly, their estimates for owner/operator fines varied from $\$ 0$ to $\$ 2$ million dollars. Individual fines were always seen as lower than company fines, often by one or two orders of magnitude. Fifty percent of respondents believed that if a company official were incarcerated, the length of the sentence served would be six months or less. The longest period of incarceration envisaged was ten years. ${ }^{24}$

\section{THE EFFECT OF KNOWLEDGE ON RISK PERCEPTION}

There was no clear association between knowledge of enforcement actions against other firms and our measures of respondents' perceptions of the risk of detection and punishment. Five linear regression analyses were performed, each modeling a risk perception variable (likelihood of facility closure, detection, company fine, jail, individual fine) as a function of company size, ${ }^{25}$ degree of professionalization, ${ }^{26}$ knowledge (general deterrence), ${ }^{27}$ and industry. All models were significant, but the overall goodness of fit for the model of perceived risk of company fine was particularly weak. ${ }^{28}$ In general, knowledge variables were not significantly associated with risk perception-nor was the direction of statistically insignificant associations consistent for all models. However, recall of particular examples was statistically significant in the "risk of company fine" model.

After we gave respondents a short description of the signal case as a hypothetical case, we asked what they thought the possible size of the associated company fine might be (assuming the infraction was detected and a fine was levied). A large number of respondents (68) could offer no estimate. For those that did, the majority (68 percent) of respondents underestimated the fine actually imposed by an order of magnitude, 28 percent gave an estimate of the same order of magnitude, and 4 percent overestimated the fines by an order of magnitude. Those respondents that had heard of the signal case also tended to underestimate the fine, but less often ( 59 percent) than those who had not heard of the signal case (74 percent).

On the other hand, after being told the actual penalty in the signal case, 85 percent of respondents felt that the punishment in the case was reasonable. There was no difference in that regard between those who remembered the 
signal case and those who did not. Of the respondents who felt that the penalty had been unreasonable, slightly fewer than half ( 40 percent) felt that the punishments given were unreasonably stringent, while the remainder $(60$ percent) felt that the punishments were too lenient. These findings suggest considerable support among respondents for tougher legal sanctions against firms that had committed serious violations. And this is consistent with the notion that publicized penalties against other firms serves a "reassurance function" for firms that regard themselves as compliant "good apples."

\section{COMPLIANCE-RELATED BEHAVIOR}

As noted earlier, at the end of our interviews, after asking respondents if they recalled a signal case, respondents were asked if hearing about a fine or prison sentence at another company in their industry ever made them respond by reviewing their environmental programs or changing aspects of their operations or compliance program. We regarded a company as having "taken an environmental action" if they reported having taken any of the actions listed in Table 2. Overall, 65 percent of facilities had taken an environmental action. ${ }^{29}$

In response to general deterrence signals, as shown in Table 2, facilities were most likely to review their programs ( 57 percent did) than to change any aspect of their behavior, and least likely to change their employee training (only 23 percent of facilities did). However, 32 percent of facilities reported having changed equipment. This suggests that a substantial fraction of facilities respond proactively to environmental enforcement actions taken against other facilities in their industry, and that the response is strong enough in some cases to induce costly equipment changes.

\section{E. KNOWLEDGE, RISK PERCEPTION, AND BEHAVIOR}

What distinguishes firms that reported environmental actions in response to deterrence messages from firms that did not? A logistic regression model of company environmental action as a function of demographic, knowledge, and risk perception variables ${ }^{30}$ was developed. Table 3 presents descriptive statistics for the variables employed in the model. Table 4 presents the results of the logistic regression.

Company size was significantly and positively associated with the likelihood of taking environmental action. The degree of professionalization variable was not significantly associated with taking environmental action.

With respect to knowledge variables, the number of particular examples of enforcement actions that respondents could describe (0, 1 or 2$)$ was significantly and positively associated with whether a respondent reported having taken an environmental action in response to deterrence signals. On the other hand, remembering the signal case, or remembering a larger number of instances of enforcement action in the last year or two, were not significantly associated with taking environmental actions. 


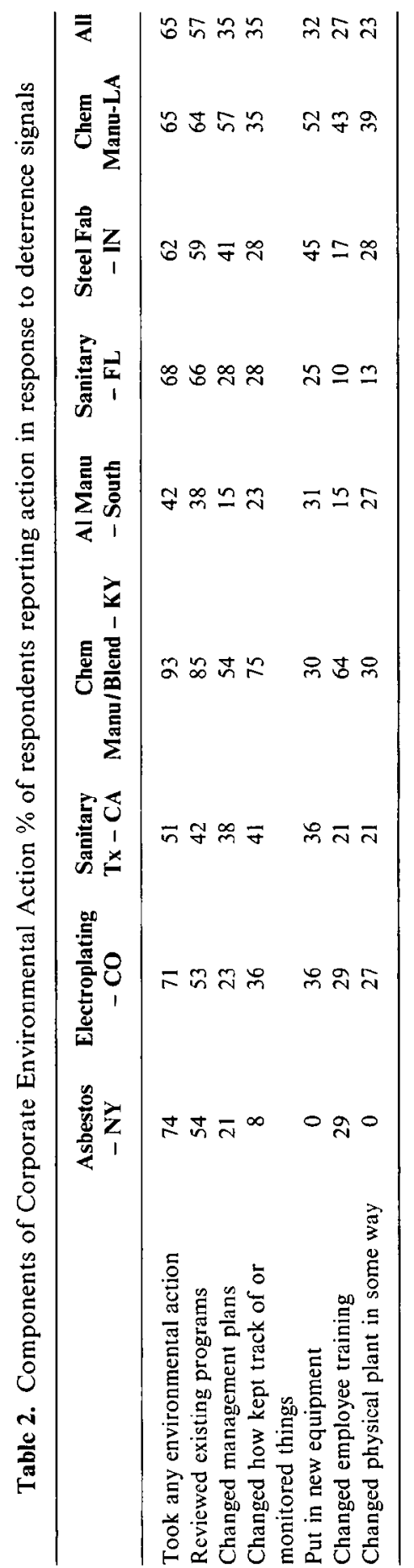

(1) 2005 Baldy Center for Law and Social Policy and Blackwell Publishing Ltd. 
Table 3. Responses to General Deterrence Messages: Descriptive Statistics

\begin{tabular}{|c|c|c|c|}
\hline & $\%$ & Valid & Missing \\
\hline Took environmental action in response to deterrence signal & 63 & 227 & 6 \\
\hline Company size & & 224 & 9 \\
\hline Large (>100 employees) & 27 & & \\
\hline Percentage time spent on environmental work & & 228 & 5 \\
\hline $0-25 \%$ & 33 & & \\
\hline $26-75 \%$ & 33 & & \\
\hline Greater than $75 \%$ & 33 & & \\
\hline No of instances of company fines recalled & & 228 & 5 \\
\hline 0 & 11 & & \\
\hline 1 & 6 & & \\
\hline $2-5$ & 25 & & \\
\hline $6-10$ & 18 & & \\
\hline$>10$ & 39 & & \\
\hline Maximum & 2,000 & & \\
\hline Remember a particular example & & 232 & 1 \\
\hline 0 & 29 & & \\
\hline 1 & 45 & & \\
\hline 2 & 26 & & \\
\hline Heard of the signal case & 42 & 229 & 4 \\
\hline Probability of Detection* & & 228 & 5 \\
\hline $0-25 \%$ & 23 & & \\
\hline $26-75 \%$ & 41 & & \\
\hline $76-100 \%$ & 36 & & \\
\hline Probability of Company Fine & & 226 & 7 \\
\hline $0-25 \%$ & 4 & & \\
\hline $26-75 \%$ & 12 & & \\
\hline $76-100 \%$ & 84 & & \\
\hline Risk** & & 225 & 8 \\
\hline $0-2500$ & 28 & & \\
\hline $2501-7500$ & 42 & & \\
\hline $7501-10000$ & 30 & & \\
\hline Magnitude of Company Fine (dollars) & & 196 & 37 \\
\hline 0 & 1 & & \\
\hline Thousands & 9 & & \\
\hline Tens of thousands & 38 & & \\
\hline Hundreds of thousands & 18 & & \\
\hline Millions or more & 34 & & \\
\hline Probability of Facility Closure & & 219 & 14 \\
\hline 0 & 50 & & \\
\hline $1-10$ & 35 & & \\
\hline $11-25$ & 11 & & \\
\hline $26-75$ & 3 & & \\
\hline $76-100$ & 1 & & \\
\hline
\end{tabular}

Notes: *Probability of Detection $=$ Response to the question: "on a scale of 0 to 100 , what do you think the chances are that the plant (in hypothetical based on signal case) would be found out by law enforcement?" Estimated Probability of Company Fine, Magnitude of Company Fine, and Probability of Facility Closure measures based on similar question about fate of company in hypothetical based on signal case.

** Risk = probability of detection $\times$ probability of company fine.

(C) 2005 Baldy Center for Law and Social Policy and Blackwell Publishing Ltd. 
Table 4. Logistic Regression Model of Corporate Environmental Action ${ }^{31}$ Dependent Variable: Taking environmental action in response to deterrence signals

(binary)

\begin{tabular}{|c|c|c|c|c|c|c|}
\hline & B & S.E. & Wald & df & Sig. & $\operatorname{Exp}(B)$ \\
\hline \multicolumn{7}{|l|}{ Demographic Variables } \\
\hline Company size (largelsmall) & 1.254 & 0.491 & 6.529 & 1 & 0.011 & 3.504 \\
\hline Degree of Professionalization & 0.008 & 0.006 & 1.838 & 1 & 0.175 & 1.008 \\
\hline \multicolumn{7}{|l|}{ Knowledge Variables } \\
\hline Number of instances of company fines & 0.002 & 0.002 & 0.840 & 1 & 0.359 & 1.002 \\
\hline Recall particular examples $(0,1$, or 2$)$ & 0.980 & 0.289 & 11.516 & 1 & 0.001 & 2.665 \\
\hline Recognize signal case & 0.386 & 0.405 & 0.908 & 1 & 0.341 & 1.470 \\
\hline \multicolumn{7}{|l|}{ Risk Perception Variables } \\
\hline Risk $=$ prob of detection $\times$ prob co. fine & 0.000 & 0.000 & 0.887 & 1 & 0.346 & 1.000 \\
\hline Magnitude of company fine $(0,1,2,3,4)$ & -0.013 & 0.184 & 0.005 & 1 & 0.944 & 0.987 \\
\hline Risk that penalties will lead to closure & 0.072 & 0.029 & 6.227 & I & 0.013 & 1.074 \\
\hline Constant & -1.775 & 0.691 & 6.608 & 1 & 0.010 & 0.169 \\
\hline
\end{tabular}

Notes: Shaded and italicized results show variables significant at or below a $p=0.05$ level.

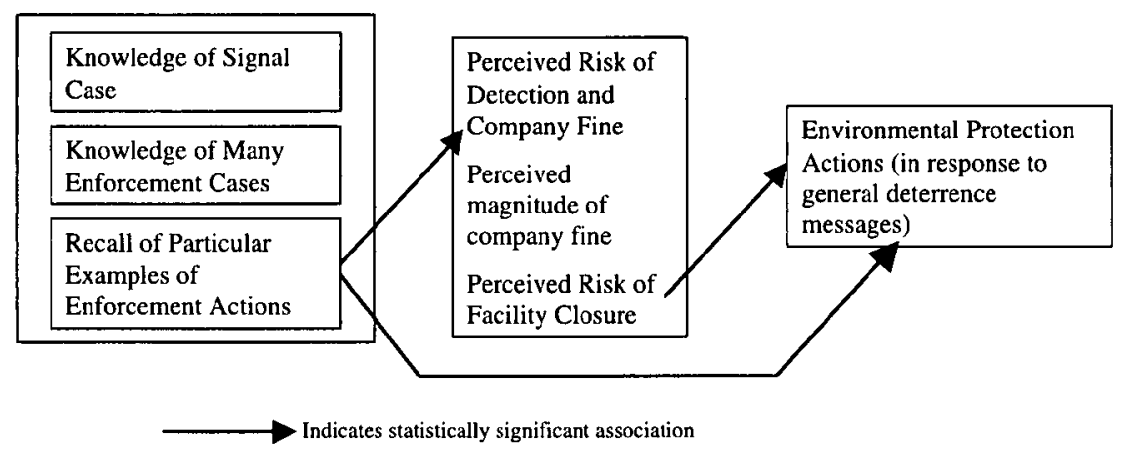

Figure 3. Summary of Results

Of the risk perception variables, only the perception that penalties might lead to facility closure was significantly associated with taking an environmental action. ${ }^{32}$ However, this result appears to be driven by the electroplating facilities in the sample, and is no longer significant $(p=0.095)$ if electroplating cases are excluded from the dataset. ${ }^{33}$ The findings regarding the associations between variables are summarized in Figure 3 above.

\section{DISCUSSION}

Classic deterrence theory predicts clear relationships between knowledge of "high profile" enforcement actions (fines and incarcerations) and improved 
compliance-related behavior. In most descriptions of the theory, (1) regulated entities are presumed to monitor their environment for information about enforcement activity and to have heard about high profile prosecutions and penalties; (2) knowledge of high profile cases is presumed to increase perceived risk of non-compliance; and (3) higher perceived risk of legal sanctions is presumed to improve overall compliance-related behavior.

Our results provide some, but very limited, support for this theory. The majority of firms (63 percent) report having, at some point in the past, taken an environmental action in response to hearing about an enforcement action at another company. Our questions did not distinguish whether or not it was knowledge of the signal case (as opposed to other penalty cases) that triggered responsive environmental action. But employing a series of assumptions, we can estimate that $10-20$ percent did respond to the signal case. ${ }^{34}$

On the other hand, we find only a weak association between increased information about other penalty cases and increased perception of legal risk. All other things being equal, respondents who recalled more particular enforcement actions against others did report significantly higher perceived risk of being fined (for violation like that in the signal case). However, no other knowledge variable was significantly associated with increased risk perception, and firms with higher risk perceptions of detection or fine were not significantly more likely to have taken an environmental action than those with lower risk perceptions.

In other ways, too, much of our data does not support the explicit general deterrence theory. Firms' quantum knowledge of fines against other companies did not appear to be very accurate in terms of the frequency of fines or their magnitude.

Respondents have not been particularly attentive to penalty information, nor have they made special efforts to obtain timely and accurate information, even though the classical deterrence model assumes that companies would study and quantify the legal risks associated with noncompliance. In addition, the lack of significant association between risk and the magnitude of fines, and taking environmental action does not support the traditional model.

We are left with a puzzle: Why do we find a direct association between recall of particular examples of prosecutions and improved environmental behavior (see Figure 2) and yet find no chain of significant associations between recall of particular examples, increased risk perception, and improved environmental behavior? Our data provides no direct answers, but it does provide evidence relevant to several of the alternative hypotheses set forth earlier.

One possibility we mentioned earlier is that it is not fear of formal legal sanctions that drives most firms to take environmental compliance actions. Rather, environmental behavior stems more from fear of informal sanctions, such as damage to a company's reputation or to an environmental manager's job or professional standing. Thus, knowledge of enforcement actions might lead to corporate environmental measures, not by increasing fear of legal penalties, but by increasing fear of informal sanctions for violations. 
We find some support for this theory in our data, but some counter-evidence as well. First, some respondents, when describing the particular examples of enforcement actions they remember, refer to cases in which individuals lost their license to practice, or their job. Our lengthy qualitative interviews with environmental managers in the chemical and electroplating industries (Gunningham, Thornton \& Kagan 2005) also suggest that, at least for some of them, fear of losing a job or being sanctioned by an employer are more salient, as possible consequences of serious violations, than are legal penalties. And returning to the larger sample discussed in this article, those respondents with greater fear of facility closure did not have, on average, higher perceptions of the size of possible fines or the probability of being fined. ${ }^{35}$ On the other hand, when describing the particular examples of enforcement actions they recalled, respondents were far more likely to focus on formal sanction ("the guy went to jail," "they got a huge fine") than they were to focus on informal consequences ("it was all over the newspapers"). Thus it appears that more dramatic legal sanctions are more likely to be remembered as salient than are informal sanctions. ${ }^{36}$

The idea that general deterrence serves primarily as a "reminder mechanism" provides a more plausible possible explanation for our findings. In this view, deterrence signals remind the "contingent good apples"-firms already committed to compliance as a general business strategy - that non-compliance can occur due to slippage in their company's own self-regulatory systems. For good apples, compliance with environmental regulations is a key to social and political legitimacy. For environmental managers in such firms, the hypothesis continues, social and self-definitions of "goodness" require continued compliance. Good apples do not calculate and calibrate the costs of non-compliance; they assume that those costs are potentially disastrous. On occasion, a deterrence signal will inform a good apple of non-compliance in their own facility stemming from employee error or deviance, or of non-compliance with a regulation they were unaware of or had interpreted incorrectly; hence the signal will spur them into more than simple confirmation routines. In this way, information could affect behavior without changing risk perceptions.

We find some support for this theory. First, the reminder function of deterrence comes through quite dramatically in our in-depth interviews (see Gunningham, Thornton \& Kagan 2005). Enforcement actions are described as "head turners" that draw the attention of environmental managers. Second, in our eight-industry survey, the particular examples described by respondents focus on large and dramatic formal sanctions with disastrous consequences. Third, our surveys suggest that actions that threaten environmental quality are seen as intrinsically "bad"-and hence that managers actually valued environmental ends. For example, of the respondents who thought that the environmental performance of the industry had improved over the last fifteen years, 36 percent believed that the reason for this improvement was (at least in part) attributable to greater awareness about the environmental impacts of industrial operations and changes in their 
industry's attitude toward the environment. Essentially, this explanation is a definition of the value of environmental ends and a definition of actions that threaten environmental quality as unfavorable. In addition, the overwhelming majority of facilities felt that the punishment in the signal case was reasonable ( 86 percent) or unreasonably lenient ( 8 percent). And lastly, the examples of non-compliance cited by respondents were often clearly judgmental in tone; this suggests support for the notion that explicit general deterrence messages serve a "reassurance function," informing contingent "good apples" (firms committed to compliance for a combination of normative, reputational, and "implicit general deterrence" reasons) that they are not foolish for doing so, since their competitors who "cheat' are getting caught and punished. Thus the legitimacy-reputation mechanisms are consistent with our findings of the pattern of association between variables.

On the other hand, the weak support for the traditional "explicit" general deterrence theory in our findings may reflect the possibility that the measures we constructed do not accurately reflect the underlying constructs we hoped they might. For example, to obtain our risk perception measures, we asked: if a company is violating in this manner, what do you perceive the risk of detection or punishment for that company to be? However, we could not ask respondents how likely they were to commit the same violations. Thus, for "good apples" we might have elicited an estimate of risk of detection for "bad apples" (not their own firm). Nor did we directly ask: Did hearing about an enforcement action at another company ever change your perception of risk?

In addition, we looked for an association between knowledge of enforcement actions and risk perception in a cross-sectional study. Thus causality cannot be inferred from our findings. Higher risk perceptions could cause greater knowledge (rather than the other way around) because people with higher risk perceptions look harder for enforcement information and remember it better. However, in either case, one would expect a significant association, which we did not find.

Furthermore, we obtained only a snap shot of current risk perceptions, but asked for an aggregate measure of behavior change, asking if companies had "ever" taken environmental actions in response to deterrence signals. Our measure thus does not rule out the possibility that firms that acted in response to deterrence signals had higher risk perceptions at that prior time. Lastly, it must be remembered that this research was conducted in the United States in the early twenty-first century, more than a quarter century after American states and the federal government started serious enforcement of environmental laws. Hence the "implicit general deterrence" mechanism has matured, so that the enforcement and normative legitimacy of environmental regulations is taken for granted by many firms. And social and political support for environmental norms has given many companies a substantial economic stake in avoiding a reputation for being bad environmental citizens. Thus, our research has little to say about the importance of explicit general deterrence messages at earlier stages in regulatory programs, when their value added may well be greater. 
Our research provides only weak support, at best, for the classical "general deterrence" hypothesis (which we would now label "explicit general deterrence"). Fewer than half (42 percent) of 229 respondents in regulated businesses recognized and remembered the specific signal case, suggesting at least partial support for the "weak signal" hypothesis. On the other hand, general deterrence seems to have a cumulative effect on the consciousness of regulated companies: 89 percent of our respondents remembered at least one instance of some company having been penalized for an environmental violation in the past year or two. And some 63 percent of the companies we surveyed reported having taken some environmental protection measures after learning about penalties against other companies. Most often, the reported reaction was to review their own compliance programs, but many also changed equipment, monitoring practices, and employee training.

Yet many relationships predicted by the classical deterrence model did not show up in our data. For example, respondents who recognized the signal case or referred to a larger quantum of other cases were not more likely to report having taken environmental action in response. Moreover, those officials who saw the risk of formal detection and punishment as relatively high were not, on average, more likely to report taking environmental measures in response to general deterrence messages. Company managers were not closely attentive to or knowledgeable about the penalties assessed against violators, generally underestimating them. This suggests to us that penalties against other firms - at least in the United States near the beginning of the twenty-first century-play a somewhat different role from the one embedded in the classical general deterrence theory, which assumes that the imminent threat of legal punishment is the primary driver of compliance efforts.

Our survey and in-depth interview (Gunningham, Thornton \& Kagan 2004) evidence, rather, suggests that for most firms, general deterrence primarily serves a reminder and a reassurance function. Most of the companics (some 63 percent of our sample) that respond to deterrence signals by taking some environmental action probably are predominantly stimulated to check whether they are in compliance; they are not firms (as assumed by deterrence theory) who know that they are not in compliance and are stimulated by legal threat to change their ways. We speculate that the mechanism by which deterrence affects the behavior of these two groups is different. For those that know they are not in compliance, deterrence cases that are exactly relevant to their particular circumstances may well increase their risk perceptions and change behavior (the classic deterrence model). But for the "good apples" - firms that are generally committed to compliance for a variety of normative and reputational reasons-each deterrent signal reinforces their perception of the need to continue compliance activities and of the potential disastrousness of non-compliance. Sometimes, a deterrence signal prods "good apples" to check and learn that they are no longer in compliance and need to take further 
action. Deterrence signals both reassure "good apples" that free-riders will be punished and remind them to make sure that they are responsible corporate citizens with no need to fear the social and economic costs that can be triggered by serious violations.

DOROTHY thornton holds a Ph.D. in Health Services and Policy Analysis from the University of California, Berkeley and currently is a research associate in Berkeley's School of Public Health.

NEIL GUNNINGHAM holds professorial research appointments in the Regulatory Institutions Network, Research School of the Social Sciences, and in the School of Resources, Environment and Society, both at the Australian National University.

ROBert A. Kagan is Professor of Political Science and Law at the University of California. Berkeley.

\section{NOTES}

1. See also studies summarized in Vandenbergh (2003: 119-22).

2. In a recent survey of members of the American Bar Association Section of Environment, Energy and Resources (practitioners of environmental law in both the public and private sectors), Ruhl et al. (2002: 26) found that "Respondents agreed or strongly agreed that noncompliance hurts the corporate public image ( 85 percent), creates friction between business and government ( 81 percent), increases administrative costs ( 82 percent), and demoralizes company personnel (74 percent)."

3. A 2003 EPA survey found that approximately 25 percent of the 6600 facilities with the largest discharges had engaged in "significant noncompliance" (U.S. EPA 2003; see also Rechtschaffen 2004: 776).

4. Summarizing a number of studies, Vandenbergh (2003: 127) concludes, "Despite the small risks of inspections and the small size of sanctions, compliance rates [for environmental regulatory requirements] are widely regarded to be higher than predicted by the standard deterrence model."

5. Vandenbergh (2003: 90) cites a study of environmental managers in the metal finishing industry (Flannery \& May 2000), which concluded that the magnitude of the human health consequences of environmental decisions is strongly correlated with expressed intentions to comply with regulations, and "when the magnitude of the consequences was high, financial cost did not affect the intended decision."

6. Cordano and Frieze (2000: 635) found that corporate environmental managers generally express attitudes strongly supporting pollution prevention.

7. Note that in many economic models of legal behavior (and the general deterrence theory), the presumption is that firms are low on duty (or that normative obligation simply is irrelevant), while firms are quite sensitive to the magnitude of legal threat.

8. Research on individual taxpayers has indicated that "fear" and "duty" tend to interact in producing compliance (or non-compliance) with income tax law. That is, taxpayers who are reminded of the threat of legal penalty for failing to report income tend to display heightened sensitivity to the normative obligation to pay taxes (Schwartz \& Orleans 1967). Conversely, taxpayers to express a stronger sense of duty to report all income also have a higher subjective estimate of the 
risk of being caught for cheating (Scholz \& Pinney 1995). However, another study found that among taxpayers with a similar sense of duty, those who had lower fear of being caught (greater opportunity to cheat) had lower levels of self-reported compliance-indicating that "fear" has independent effects (Scholz \& Lubell 1998).

9. The survey of environmental lawyers mentioned above (Ruhl et al. 2002) discovered strong agreement that the sheer number, complexity, and changeability of environmental regulations is the chief cause of non-compliance (far outranking "costs of compliance") and indeed made it virtually impossible to achieve full compliance 100 percent of the time, even for committed firms (see also Aoki, Axelrad \& Kagan 2000).

10. Vandenbergh (2003: 73-74), referring to social psychologist Shalom Schwartz's theory of norm activation, writes "an enforcement intervention may activate [in the minds of firm managers] if it provides information about the [adverse social] consequences of a noncompliant act and the individual's responsibility for or ability to prevent those consequences."

11. In terms of Figure 1, Bowles's 20 percent of unconditional compliers are "high on duty", 5 percent are low on both fear and duty, and the other 75 percent are contingently high on duty. Some legal theorists, too, have referred to the reassurance function of law enforcement. Kahan (1996: 604), for example, writes of the prevalence of "conditional cooperation," whereby, a commitment to obey the law can be undercut by a sense that violators often are not punished, because of the widespread "desire not to be suckered" (see also Kahan 1997).

12. In the smaller, in-depth study, the facilities were chosen in order to ensure that the sample included respondents from urban areas (Seattle and Spokane in Washington, Cleveland and Cincinnati in Ohio as well as rural areas; companies that operated a number of facilities in a number of states as well as those that operated only a single facility; and companies that ranged significantly in size from mom-and-pop operations to multinationals. Response rates were 36 percent ( 8 out of 22) for WA electroplaters, 45 percent $(9$ of 20 ) and for $\mathrm{OH}$ electroplaters. The most common reason given for non-response was lack of time to participate in a one-hour interview. Response rates were 38 percent ( 8 of 21 ) for WA chemical companies and 56 percent for $\mathrm{OH}$ chemical companies (10 of 18). The non-respondents do not appear to have been disproportionately "bad apples;" nor were the respondents disproportionately "good apples." Using the EPA's "ECHO" on-line data set (http://www.epa.gov/echo/compliance_report.html), we found that in 2002-03, the average "quarters in noncompliance" (according to government inspectors) for electroplaters in our Washington sample was 1.38; for Washington electroplaters who declined to participate, the figure was 1.25 , slightly less. We also compared electroplaters in our Ohio sample with all Ohio electroplaters in the EPA database, and the average quarters in noncompliance for both groups was virtually equal. Respondents in Washington more often were larger firms than were non-respondents (which nevertheless were slightly larger, on average, than the industry norm). But in Ohio respondents were about the same size, on average, as the industry norm, according to the EPA data set.

13. We included only press releases of completed enforcement actions (e.g., we did not include those simply announcing a prosecution) and excluded those involving "wholly illegal enterprises," such as firms that operated entirely outside the law (midnight dumpers, unlicensed businesses).

14. In truncating the period, we sought to concentrate on actions that were relatively more recent, so that respondents might have a better chance of remembering them, but not so recent that news of them might not have had time to circulate in the industry.

15. We compiled a list of facilities by searching EPA's Envirofacts database for facilities in the same state and SIC code as the signal facility. In addition, 
Switchboard.com and Yellowpages.com were searched for additional facilities in the same industrial categories as the signal facility, as was Hoovers.com. Where available, state databases of the relevant facilities were obtained.

16. Response rates were 100 percent for sanitary treatment facilities ( $n=40$ in Florida, 39 in California), $76 \%$ for aluminum fabricators (26/34), 75\% for steel fabricators (30/40); 73\% for chemical manufacturers and blenders (29/40), and $69 \%$ for Colorado Electroplaters (22/32), $75 \%$ for asbestos abatement companies in New York (24/32) and 70\% for chemical manufacturers in Louisiana (23/33). Based on our examination of relative noncompliance rates (according to EPA data) for electroplating firms in Washington and Ohio, see note 13 above, it appears likely that respondent firms in the eight-industry survey, too, were not disproportionately those with above-average compliance records, as compared to either non-respondents or the industry norm.

17. The median penalty in this Louisiana example was $\$ 16,750$ with a range of $\$ 2,300$ to $\$ 1.6$ million. Five of the thirty-one penalties ( 16 percent) exceeded $\$ 100,000$.

18. All other things being equal, aluminum fabricators recalled significantly fewer particular examples of enforcement actions than facilities in any other industry. (Logistic Regression: Recall spc. ex. $=\mathrm{f}($ \#employees, professionalization, industry). No other variables significant.

19. All other things being equal, electroplaters $(71$ percent) were significantly more likely to recognize the signal case than were respondents from any other industry. The more professionalized the environmental staff person, the more likely they were to remember the signal case (Logistic Regression: Recall spc. ex. $=f(\#$ (\#ployees, professionalization, industry). No other variables were significant.

20. We chose a random sample of forty EPA press releases announcing legal sanctions against violators, and searched for media coverage via Lexis-Nexis, major newspapers, local newspapers, radio and television news transcripts, industry news outlets, newswires and regional newspaper files. Based on coverage, we found that only ten of the press releases received wide media coverage ( 16 to 145 stories); fourteen cases received "low" media coverage (0-6 stories); and sixteen received "medium coverage (7-15 stories). The apparent threshold for obtaining wide media attention was an unusually large fine (in excess of $\$ 4$ million) or an unusually long jail sentence (greater than 41 months).

21. The more of her time a respondent spent on environmental work the more likely she was to recognize the signal case. However, less professionalized environmental staff were just as likely to be able to describe particular examples of environmental penalties. In general, knowledge did not vary significantly by industry. Only aluminum fabricators were significantly less likely than facilities in other industries to be able to describe a particular example of an environmental penalty.

22. For 50 percent of respondents, there was no chance that environmental penalties would eventually lead to facility closure, and 85 percent of facilities believed the probability of such a closure was 10 percent or less-but for the remaining 15 percent of respondents, the risk of forced closure was real, and in a very few cases, substantial. Electroplaters and asbestos abatement companies were likely to think that fines might lead to facility closure. In fact, none of these respondents felt that the probability of facility closure was zero. Conversely, the vast majority of sanitary treatment facility respondents in both California and Florida deemed closure impossible, which seems a reasonable assessment given the indispensability of their function. Some chemical manufacturing facilities viewed the probability of facility closure as reasonably high, while most aluminum fabricators and steel fabricators viewed it as highly unlikely.

23. Electroplaters had a much higher risk perception than all other industries (median probability is above 50 percent, while for all other industries it is at or below 20 percent). 
24. A large number of respondents did not give an estimate of the size of the penalty. Many felt that the penalty would depend too much on the specifics of the case and felt uncomfortable giving a single number, or even a range of possible penalties. Others ( 5 percent of respondents) said they had no idea of the size of a possible company fine, 7 percent had no idea of the size of a possible individual fine, and 13 percent had no idea of the length of a possible jail or prison sentence.

25. Company size is divided into "large" (100 or more employees) and "small" (less than 100 employees).

26. Measured as a percentage of the time the respondent spent on environmental work.

27. Three different measures used. First, the quantum of fines recalled, categorized as: none, 1 or 2,3 to 9,10 to 15,16 to 30 , more than 30 . Second, the number of particular cases recalled and described (none, one or two), and third, whether or not the signal case was recalled.

28. Reference industry $=$ sanitary treatment facilities in Florida.

Facility Closure: $\mathrm{df}=190, F=10.168, p<0.000$, Adj $R^{2}=0.367$, Sig Vars: Asbes, Elec, Steel, Chem-KY (all +ve)

Detection: $\mathrm{df}=195, F=3.679, p<0.000$, Adj $R^{2}=0.142$, Sig Vars: Chem-KY (+ve) Company Fine: df $=193, F=1.851, p=0.043$, Adj $R^{2}=0.050$, Sig Vars: Particular Exs (+ve)

Individual Fine: $\mathrm{df}=185, F=2.390, p=0.007$, Adj $R^{2}=0.083$, Sig Vars: Steel (-ve) Jail: $\mathrm{df}=186, F=3.532, p<0.000$, Adj $R^{2}=0.140$, Sig Vars: Elec $(+v \mathrm{c})$ SanTx$\mathrm{CA}(+\mathrm{ve})$

29. One reviewer speculated that that respondents may have over-reported having taken an environmental action in response to learning about sanctions against other firms, because they may have thought that would portray their firm in a more positive light. But as will be shown in the next section, the most common environmental response reported by respondents was merely to check their compliance systems, and nothing more, which indicates that they were not inclined to exaggerate about how responsive they were to deterrence messages. Conversely, one could also speculate that firms would be likely to under-report environmental action in response to news of sanctions, because that might suggest that they had not done enough in the past. Yet we think that unlikely, too, since the most common reported response was only to review current corporate compliance systems.

30. Demographic variables included: (1) company size, and (2) degree of professionalization, as measured by the percent of time spent on environmental work. Knowledge variables have been described earlier. The number of instances of individual fines and the number of instances of jail/prison sentences were not included in the model because of the high degree of correlation between variables. The company fine variable was chosen because company fines are the most common enforcement tool in use.

Risk perception variables included the probability of detection multiplied by the probability of a company fine, and the magnitude of the company fine. The magnitude of the company fine was given as $\$ 0=0, \$ 1,000 \mathrm{~s}=1, \$ 10,000 \mathrm{~s}=2$, $\$ 100,000 \mathrm{~s}=3$ and $\$ 1,000,000$ s or more $=4$. These risk perceptions were for serious infractions for which federal EPA headquarters had written press releases, and varied from one industry to another. The probability of individual fines and jail sentences were omitted because the number of missing values would seriously bias the data.

The probability that enforcement would lead to facility closure was also included in the model, this variable was directly comparable across all industries.

31. Number of cases included in the analysis $=176(=75.5 \%$ of all cases $)$. The model chi-square is 50.706 which is significant at $p<0.000$. The -2 Log likelihood value is 175.150 and the Cox and Snell $R^{2}$ is 0.250 . A second model was also run including dummy variables for each industry. The addition of this block of 
variables was not significant at a 0.05 level and so these variables were not included in the model (chi-square $=9.812, \mathrm{df}=7, \mathrm{p}=0.199$ ). A correlation matrix was calculated. No bivariate correlations exceeded 0.30 .

32. These results remained essentially unchanged if perceived risk of detection and perceived risk of company fine were entered in the model separately, instead of their product. Neither risk, the perceived risk of a company fine, nor perceived risk of detection were significant, even when the recall of particular examples was dropped from the model (this was done because recall of particular examples was significantly associated with perceived risk of company fines).

33. The regression model action $=f$ (size, professionalization, instances, particular examples, signal case, risk, magnitude of fine, facility closure) was run eight times, each time excluding those records from a single industry. Recall of particular examples was found to be significant for all of these models. Size was found to be significant for all but one model (the model excluding chemical companies in Kentucky). And the perceived risk of facility closure was found to be significant for all but one model (the model that excluded Colorado electroplating facilities).

34. About 60 percent of facilities reported they had taken an action in response to hearing about some legal penalty against some other company. About 40 percent had heard of the signal case. If we apply the 60 percent response figure to the 40 percent, then perhaps 24 percent of facilities took environmental action in response to the signal case. Since that may overestimate the signal case response, our guess is that $10-20$ percent would be more realistic

35. They did, however, have higher average perceptions of the risk of an infraction being detected.

36. However, our study of media coverage of enforcement activities suggests that more dramatic sanctions receive more press coverage, so there might well be an association between publicity and other informal sanctions and more dramatic legal sanctions.

\section{REFERENCES}

Aoki, Kazumasu, Lee Axelrad, and Robert A. Kagan (2000) "Industrial Effluent Control in the United States and Japan." In Regulatory Encounters: Multinational Corporations and American Adversarial Legalism, edited by R. A. Kagan \& L. Axelrad. Berkeley: Univ. of California Press.

Ayres, Ian, and John Braithwaite (1992) Responsive Regulation. New York: Oxford Univ. Press

Bardach, Eugene, and Robert A. Kagan (2002) Going by the Book: The Problem of Regulatory Unreasonableness. Rev. ed. Philadelphia: Transaction Publishers.

Bowles, Chester (1971) Promises to Keep. New York: Harper \& Row.

Braithwaite, John, and Toni Makkai (1991) "Testing an Expected Utility Model of Corporate Deterrence," Law \& Society Review 25: 7-40.

Cordano, Mark, and Irene Hanson Frieze (2000) "Pollution Reduction Preferences of U.S. Environmental Managers," Academy of Management Journal 43: 627.

Flannery, Brenda, and Douglas May (2000) "Environmental Ethical Decision Making in the U.S. Metal-Finishing Industry," Academy of Management Journal 43: 642 .

Gray, Wayne, and John T. Scholz (1991) "Analyzing the Equity and Efficiency of OSHA Enforcement," Law \& Policy 13: 185-214.

Gray, Wayne B., and Ronald J. Shadbegian (2005) "When and Why Do Plants Comply? Paper Mills in the 1980s," Law \& Policy 27: 238-61. 
Guniningham, Neil A., Dorothy Thornton, and Robert A. Kagan (2005) "Motivating Management: Corporate Compliance in Environmental Protection," Law \& Policy 27: 289-316.

Gunningham, Neil, Robert A. Kagan, and Dorothy Thornton (2003) Shades of Green: Business, Regulation and Environment. Berkeley, Calif: Stanford Univ. Press.

Kagan, Robert A., Neil Gunningham, and Dorothy Thornton (2003) "Explaining Corporate Environmental Performance: How Does Regulation Matter?" Law \& Society Review 37: 51-90.

Kagan, Robert A., and John T. Sholz (1984) "The Criminology of the Corporation and Regulatory Enforcement Styles." In Enforcing Regulation, edited by K. Hawkins \& J. M. Thomas. Boston: Kluwer-Nijhoff.

Kahan, Dan M. (1996) "What Do Alternative Sanctions Mean?" University of Chicago Law Review 63: 591-653.

Kahan, Dan M. (1997) "Social Influence, Social Meaning, and Deterrence," Virginia Law Review 83: 349-95.

Malloy, Timothy (2003) "Regulation, Compliance and the Firm," Temple Law Review 76: 451-531.

May, Peter J. (2004) "Compliance Motivations: Affirmative and Negative Bases," Law \& Society Review 38: 41-68

Mehta, Alex, and Keith Hawkins (1998) "Integrated Pollution Control and Its Impact: Perspectives From Industry," Journal of Environmental Law 10: 61-77.

Mendeloff, John, and Wayne B. Gray (2005) "Inside the Black Box: How Do OSHA Inspections Lead to Reductions in Workplace Injuries?" Law \& Policy 27: 219-37.

Prakash, Asseem (2000) Greening the Firm: The Politics of Corporate Environmentalism. Cambridge: Cambridge Univ. Press.

Rechtschaffen, Clifford (2004) "Enforcing the Clean Water Act in the Twenty-First Century: Harnessing the Power of the Public Spotlight," Alabama Law. Review 55: $775-814$.

Ruhl, J. B., James Salzman, Kai-Sheng Song, and Han Yu (2002) "Environmental Compliance: Another Integrity Crisis or Too Many Rules?' Natural Resources \& Environment 17: 24-29.

Scholz, John T., and Neil Pinney (1995) "Duty, Fear and Tax Compliance: The Heuristic Basis of Citizenship Behavior," American Journal of Political Science 39: 490.

Scholz, John T., and Mark Lubell (1998) "Trust and Taxpaying: Testing the Heuristic Hypothesis," American Journal of Political Science 42: 398-417.

Schwartz, Richard D., and Sonya Orleans (1967) "On Legal Sanctions," University of Chicago Law Review 34: 274-300.

Spence, David (2001) "The Shadow of the Rational Polluter: Rethinking the Role of Rational Actor Models in Environmental Law," California Law Review 89: 917-98.

U.S. Environmental Protection Agency (EPA) (2003) A Pilot for Performance Analysis of Selected Components of the National Enforcement and Compliance Assurance Program. Washington, DC: U.S. EPA Office of Enforcement and Compliance Assurance.

Vandenbergh, Michael (2003) "Beyond Elegance: A Testable Typology of Social Norms in Corporate Environmental Compliance," Stanford Environmental Law Journal 22: 55-144. 